\title{
A GENERAL OVERVIEW OF ENGLISH AS A FOREIGN LANGUAGE IN THE CONTEMPORARY ROMANIAN HIGHER EDUCATION Maria-Miruna CIOCOI-POP
}

\author{
"Vasile Goldiş" Western University, Arad, Romania \\ miruna_ciocoipop@yahoo.com
}

\begin{abstract}
It goes without saying that the lingua franca's significance in our day and age is fundamental. International and European integration, as well as the modern process of globalization have lead to the incremented usage of the English language. As a result, English as a foreign language has become a relevant subject taught for a minimum of one year within almost all bachelor programs in the Romanian higher educational system. As an integrated part of the European Union, Romania is constantly undergoing a process of delivering higher education - services at European standards; thus, EFL courses, seminars and practical courses in Universities are becoming an important mile stone in the European development of students.
\end{abstract}

Keywords: English, teaching, education, foreign language

\section{Introduction}

English as a foreign language is, beyond a doubt, the most frequently taught foreign language in the world. It is the apparatus that assists so many people of different origins and backgrounds in creating links and bonds. It is known for a fact that EFL is taught in most countries in the European Union and the world and Romania is no exception to this rule. EFL is taught at all levels of the educational system, but in what follows, we will focus on higher education and why English as a foreign language is turning into a veritable milestone in the evolution of Romanian undergraduate students.

2. English as a foreign language in Universities

The question of how far-reaching the English language-usage truly is, is unproblematic, since it is the world-wide language of business, diplomacy, administration, traffic, technology, information and data transmission, music, and the list can go on. Regardless of what country one travels to, where one has to perform, say, a bank operation or perform any given task in a foreign country, English is the main medium of communication. Thus, the fact that an overwhelming number of academic curricula all over the world include English is highly comprehensible.

No matter the field of study, English is always the student's first option for the foreign language class, which is quite understandable in the case of Romanian undergraduate students, who were taught English since kindergarten or first grade. American pop culture and its abundant dispersing via movies, music and the internet is to be encountered on a daily basis and facilitates students' predilection towards the English language. IT students, for instance, are highly familiar with the English vocabulary, because at the core of their "jargon" lies the English computer vocabulary. What I am trying to point out is the fact that EFL holds an important place in the Romanian higher education system and the fact that it is implemented as mandatory subject in academic curricula stands testimony to its function and position within the European Romanian education. 
Several articles have tackled the subject of English being the main language in global higher education, which shows that this is not necessarily a new phenomenon. What is nevertheless worthy to be pointed out is the new functions that it is fulfilling lately. A rising amount of undergraduate and graduate students are exploring the advantages of international higher education and programs allowing them to study abroad, be it for a semester or several years. Programs such as the Erasmus one are yet another constructive outcome of the globalisation and international joining together of universities. What is more, studying abroad is a modern necessity, which opens several cultural and educational paths and sheds new light upon students" "Weltanschauung".

Although some voices have expressed their concern regarding the dominance of English in the global academic field, in fear of losing individuality and originality, the overwhelming number of English language based studying programs, international conferences or journals using English as their official language, online or in class courses delivered in English are all reasons to believe that the ascendancy of English in the academia is an aid rather than a threat for international scholarly practices. The two-sidedness of the emergence of the English language in Universities is eloquently underlined in the following excerpt from an article published by The Guardian, on the subject of English as the dominant language of higher education: "Globally, English has been key to academic collaboration, through research activity, events and communications, both inside and between institutions themselves. But as Mary Jane Curry, co-author of 'Academic writing in a global context', points out, the growing dominance of English in academia has put scholars from non-English speaking countries at a disadvantage in publishing and sharing research across borders" [1]. One of the goals of both state- and private universities is to attract international students. This is not only a marketing strategy but it truly enlarges the international visibility of these knowledge based institutions. Attracting international students does not bring solely advantages but a series of responsibilities as well, like, for instance, thorough English language testing during and after enrolment for both students and the academic staff. Educators and faculty members now have to offer their courses in English, which is an additional manifestation of English as the lingua franca of academia.

\subsection{English as a foreign language in Romanian academia}

We have already stressed the idea that the English language is the lingua franca of higher education and this, of course, encompasses the Romanian higher education system as well. In the same fashion in which universities all over the world are seeking to internationalise their educational programs and offers, Romanian universities are promoting courses in the English language, as a result of globalisation both in everyday life and on educational basis. Whether promoting EFL or courses in English for native speakers has economic, political or cultural implications is debatable; what remains certain is that teaching EFL to Romanian students means keeping with the pace of modern day requirements of employers and society in general and offering English courses and materials to international students is a natural step taken by the Romanian higher education system which keeps up with European and international demands and evolution: "English is playing a key role in how universities are evolving. Drivers of change for higher education institutions include student demands to be able to compete in a globalised labour market, mobility trends, and the need for intercultural and language skills. These developments are forcing institutions to address traditional methods of teaching and learning, and to promote mobility for staff and students through exchange programmes, dual or double degrees and research in foreign countries [2]. 
The private higher education system in Romania is both a partner and, naturally, a competitor in the academia. The number of degrees taught in English has increased in this part of the educational system as well, as a natural effect of the need to enhance their visibility and attract as much candidates as possible. The application of students in Europe is growing by the year and the Romanian higher education system is trying to attract a considerable percentage. Using the English language is a must and a great necessity in this case, especially since the Romanian academic system is becoming an active part of the Erasmus and Erasmus Plus mobility programs for both teaching staff and students.

Through these programs, the Romanian higher education promotes multilingualism, multiculturalism and diversity but, at the same time, acknowledging the binding role of the English language in this context. The issue is more than teaching English as a foreign language, it is teaching English correctly, as a medium for the education process, as John Knagg, head of research and consultancy for English for the British Council, puts it: "English as a medium of instruction, however, is only worth doing if it is done well...once it moves away from Buckingham Palace or Stratford-on-Avon, then non-native teachers can become assessors and experts, and this is a difficult issue to tackle. If EMI is done badly then it is a bad thing as it can lead to failure in the education process. The issue is not the study of English as a foreign language, but using English as medium of transmitting advanced knowledge; the student is expected to already know English. We want to work with organisations to make sure EMI is done in a quality way" [3].

The Romanian higher education system is trying to globalise its offer, in the present day context where IT, the online educational system and distance learning programs are an actuality. In order to attract faculty members and students from all over the world, universities in Romania - like veritable knowledge based organisations eventually had to convey educational programs in English. Using this lingua franca in academia is no longer a fashion, but a necessity, an inevitable stage in the development of global education systems. It goes without saying that this process is far from being an easy one. Faculty staff has to deliver knowledgeable information in a language that is not their mother tongue and to clarify key concepts in a language that is not the mother tongue of several foreign students. Linguistic problems may arise especially when difficult concepts have to be made clear. Oversimplifying or obscuring meaning are not options, or else the educational process of conveying meaningful information is affected. The usage of English as a foreign language has very many implications in the progression of delivering higher education in Romania, among which a changing of teaching strategy towards a linguistic oriented policy, the lingua franca being implemented in university administration but also encourage and advertise a multi-cultural learning environment.

An additional reason for the importance of EFL is the reassessing of methodology, teaching practices and pedagogy. When it comes to these three areas, innovation and perfection are always welcome. Redefining teaching methods by introducing EFL leads to another positive aspect brought forth by the lingua franca of academia, namely emphasizing the importance of foreign languages in academia in general and of English in particular. Testing linguistic abilities is or should be a sine qua non for both academic staff members and students alike. The more globalisation influenced the academic sphere, the more Romanian universities had to work on their administration strategies and preparing teaching staff and materials for the multicultural educational process, in which the English language is, as we have uttered before, indispensible.

\section{EFL - a step towards the reform of Romanian education}


We have already highlighted a few general ways in which teaching and studying in English has influenced the Romanian higher education system. Acting in accordance with European criteria, numerous higher education institutions expanded their horizon by "creating a subsector for ethnic minorities in which all teaching activities and examinations are carried out in minority languages" [4]. Alongside decentralisation, gender equality, ethnic diversity or modernising teaching and learning processes, the emergence of EFL in all layers of the Romanian academia, be it in the classroom, in administration or in research has contributed significantly to the reform of higher education in Romania. By implementing programs based on English language, universities in Romania have facilitated academic mobility and enlarged the research platform. The fact that the diploma supplement, implemented beginning with the year 2000 in higher education institutions, is drafted in English is not a coincidence. It was designed as to be recognized within the European Union, therefore the English language is a strong medium and a tool for undergraduate and graduate students and alumni to be integrated in the international labour market.

That EFL in universities lies at the basis of academia internationalisation is a fact. What is more, internationalisation is one of the most strived for objectives in academia nowadays: "According to the last Trends report (Sursock and Smidt, 2010), internationalization is seen as the third most important driver of change in the 20072010 period, and will move to the first place by 2015 [5]. Attracting foreign students has been a top priority for Romanian universities beginning with the 70 's, as pointed out in the following lines from the work "Higher education reforms in Eastern Europe. A Hungarian-Romanian case study": "In Romania, starting from the $70 \mathrm{~s}$, the communist regime has pursued a policy of 'internationalization', seeking to attract students from the communist block, but from Asia and Africa as well (Nicolescu et al., 2009). The main mechanisms were lower tuition fees, as compared to neighboring countries, special facilities (preparatory years to learn Romanian, better dorms, etc.). In the $70 \mathrm{~s}-80 \mathrm{~s}$ decade, Romania ranked in the first 15 providers of higher education for foreigners (Nicolescu et al., 2009), trend which slowed down in the 80 s, due to economic decline." [6]. The authors go on to underline that: "After 1989, Romania tried to regain the interest of international students. In the early 1990s, a program dedicated to Central and Eastern Europe, TEMPUS, has allowed students and staff to learn and teach in Western Europe."[7]

\subsection{Prospects for EFL in Romanian academia}

In the very general description above, we have provided examples of how EFL influenced the evolution of higher education in Romania. The question is: what are the prospects, how will EFL further advantage the educational system or in what measure will it influence future academic existence? Beyond the shadow of a doubt, Romanian universities will strive to meet the needs of the market, to revise and update their curricula as to keep pace with the European norms and design applicable courses in view of delivering capable and skillful graduates on the labor market. And because teaching is based on the requirements of the market, we believe that the influence of EFL will continue to grow in the following years. A growing number of master and even $\mathrm{PhD}$ students can be noticed in Romania, also due to employer demands and the expansion of academic research in the past years. In this context, EFL-usage should become a common practice among students and Faculty members alike. The Romanian higher education is of interest to foreign students especially because of the fees, which are significantly lower than in their own countries. In order to keep this tendency rising, universities will have to 
dwell upon the development of EFL classes. What is more, Romanian universities have built partnerships with the business environment, in the sense that they prepare competent students and the employers offer internships or part time jobs to the students, whom they prepare for future positions in their companies. The role of the English language in business, companies, labor market and in our present culture and society is undeniable; which means that universities will continue to deliver courses in the academic lingua franca, which, notwithstanding the economic development of China, continues to be English.

\section{Conclusion}

After having discussed just a few important aspects on the relevance of English as a foreign language in the contemporary Romanian higher education, we dare say that the academic lingua franca being English is but a natural consequence in our modern academic life, characterized by interculturalism, multiculturalism, external and public relations. Up to the present moment English is holding strongly to its central position as lingua franca. It remains open to analysis what and if something will change with the visible emergence of the Asian world and whether the Asian boom will influence academic language as well.

\section{References}

[1] Shaw, Claire, Is English still the dominant language of higher education?, http://www.theguardian.com/higher-education-network/2013/feb/13/english-languageinternational-higher-education

[2] Rigg, Paul, English as the lingua franca of higher education?, Issue No. 297, 2013. http://www.universityworldnews.com/article.php?story=20131121152245865

[3] Ibidem

[4] Nicolescu, Luminiţa, The impact of the Romanian higher education reform on the university's financial and academic management, http://www.policy.hu/nicolescu/The\%20higher\%20education\%20reform\%20in\%20Ro mania.htm

[5] Vasilache et al., Higher Education Reforms in Eastern Europe. A Hungarian-Romanian Case Study, Management and Marketing Challenges for the Knowledge Society, Vol. 7, No. 2, pp. 295-322, 2012.

[6] Ibidem

[7] Ibidem 